\title{
Quantification in the Ontology Room
}

\author{
Bradley RETTLER ${ }^{\dagger}$
}

\begin{abstract}
There is a growing movement towards construing some classic debates in ontology as meaningless, either because the answers seem obvious or the debates seem intractable. In this paper, I respond to this movement. The response has three components: First, the members of the two sides of the ontological debates that dismissivists have targeted are using different quantifiers. Second, the austere ontologist is using a more fundamental quantifier than her opponent. Third, the austere ontologist's more fundamental quantifier is a restriction of her opponent's quantifier. This response takes seriously the intuition that there is something wrong with the ontological disputes, but does not entail dismissivism.
\end{abstract}

\section{Introduction}

Within metaphysics there is ontology, and there is meta-ontology. For (at least) the last 71 years, those who do ontology (hereafter 'ontologists') have been trying to answer the question, "What is there?" A typical ontological question schema is "Are there $x \mathrm{~s}$ ?", or "Do $x$ s exist?", where ' $x \mathrm{~s}$ ' is filled in with 'tables' or 'temporal parts' or the like. ${ }^{2}$ Meta-ontologists have been trying to answer questions about the ontological questions: "Are ontological questions meaningful?" "Do ontological questions have mind-independent answers?" "Are ontological disputes substantive?"

Ontologists usually presuppose an affirmative answer to these meta-ontological questions, ${ }^{3}$ but an increasing number of metaphysicians have been answering one or more of the meta-ontological questions in the negative; following Bennett

\footnotetext{
${ }^{\dagger}$ Department of Philosophy and Religious Studies, University of Wyoming, United States; Email: rettlerb@gmail.com

1 Asked and answered in Quine (1948) with "everything”, and then discussed repeatedly since.

2 Most, though not all, have treated 'are there $x$ s?' and 'do $x$ s exist?' as meaning the same thing.

3 Although Jenkins (2010) shows that the answers to these meta-ontological questions are independent.
} 
(2009), I shall call them 'dismissivists'. ${ }^{4}$ In support of their position, some dismissivists argue that ontological debates have been raging for years, and we are no closer to resolving them than we have ever been; therefore, there must be something wrong with the enterprise of ontology. Usually dismissivists say that ontological questions have obvious answers; the standard example is the question of whether there are composite objects like chairs, but similar things can be said about the questions of whether there are properties, fictional characters, musical works, and the like. "Of course there are chairs (and properties and fictional characters and musical works)", the dismissivist says, "and we needn't take seriously any argument to the contrary". Those who deny the existence of such things - "austere ontologists", I shall call them - are not just wrong, but obviously wrong, say the dismissivists.

\section{Responding to the dismissivist}

In this paper, I offer a new response to the dismissivist. According to my response, the austere ontologists who answer the ontological questions in unintuitive ways (by saying that there aren't any properties or numbers or tables or fictional characters) are restricting their attention to the things ontologists should care about qua ontologists ${ }^{5}$ and saying that tables and chairs and properties and fictional characters aren't among them. ${ }^{6}$ The things ontologists should care about are the fundamental things. So when they say, "there are no tables" and "there are no properties" and the like, these austere ontologists are using a more fundamental quantifier (which I shall call ' $\exists_{F}$ ') than the English quantifier (which I shall call ' $\exists_{E}$ '), and $\exists_{F}$ is a

4 The dismissivist camp includes Carnap (1950), Chalmers (2009), Goggans (1999), Hirsch (2005), Hofweber (2009), Putnam (2004), Sidelle (2002), Sosa (1999), Thomasson (2008) and 2009, and van Fraassen (2002). Bennett (2009) is also a dismissivist, but only with respect to the debate about when some things compose another thing.

5 I load the deck by saying that austere ontologists are succeeding at getting at the more fundamental things by restricting their quantifiers, because I think they're right. If one thinks that the things to which austere ontologists are restricting their quantifiers are not the fundamental things, then one should preface all these claims with "are trying to".

6 This is what Korman (2015a) calls a "hermeneutic strategy". The main thrust of Korman's paper is arguing against 'revolutionary strategies', where one simply stipulates that there is a fundamental quantifier and starts using it. But he does have one objection to the hermeneutic strategy: it seems like austere ontologists have changed their minds when they start saying in the ontology room that there are no tables, and that austere ontologists would report feeling like they changed their minds. But I don't think this is true - at least if they continue to say that 'there are tables' or 'there are properties' is true in some contexts. I think they would say that they never really thought that there are tables and such in the fundamental sense of 'there are'; they just didn't have the vocabulary to state it. A good example is Field (1980), who presupposed the Quinean view in the first edition of the book but then reconsiders it and opts for "a more relaxed ontological attitude" in the second edition. 
restriction of $\exists_{E} \cdot{ }^{7}$ The reason, then, that the answers that austere ontologists give to the ontological questions seem unintuitive is that we take the austere ontologists (and they often take themselves) to be using the ordinary English quantifier, but in fact they are using a more fundamental quantifier; it just looks and sounds the same as the English quantifier. And this is just a simple case of quantifier restriction, where the austere ontologists restrict the quantifier to fundamental things. There are three ways of understanding quantifier restriction, and I'll show that according to each way, the fundamental quantifier is a restriction of the ordinary English quantifier.

My response to the dismissivist allows the ontologist to say that ontological questions are substantive - at least, when the quantifier in question is the fundamental quantifier; the reason they don't seem substantive is that the parties to the ontological disputes have been using quantificational expressions ( 'there is', 'there are', 'exists', and the like) differently. This might initially seem like a version of dismissivism, because it says that the parties are talking past each other. But the fact that the disputes are substantive when 'there is' means the fundamental quantifier is why this response doesn't entail dismissivism. ${ }^{8}$ One side has been using the fundamental quantifier and the other side has been using the English quantifier. ${ }^{9}$ This explains the dismissivist intuition, but in a way that vindicates ontology when the debates are refocused.

Some have suggested that ontology ought to be about what's fundamental, or what grounds what, or what the truthmakers for our sentences are. ${ }^{10}$ And sometimes such people say that we should just stipulate a most fundamental quantifier, and then just start using that quantifier when we're doing ontology. ${ }^{11}$ My approach in this paper is not in conflict with these approaches, but it does not endorse either of them. My proposed response is not a view about what ontologists ought to be doing, but a view about what many ontologists have already been doing. Austere ontol-

7 For ease of use I'll stop affixing 'existential' all the time. This paper is solely about the 'there is' and 'there are' and 'exists' and their meanings, and not 'for all' and 'every' and their meanings; it's about existential quantificational phrases and existential quantifiers, not universal quantificational phrases and universal quantifiers.

${ }^{8}$ Although if one thought that the claim that the two sides are talking past each other is sufficient to make one a dismissivist, then that's fine; it's just a term. The point is that these disputes are very close to ones that are substantive, and we should be having the substantive debates. This is not to say, though, that the disputes would not be substantive if 'there is' were understood in the sense of some less-than-fundamental quantifier; I am merely offering a sufficient condition for substantivity, not a necessary one. Thanks to a referee for raising this point.

9 A further problem is that many disputants think that both parties are using the same quantifier.

10 See Sider (2004) and 2009 and 2011, (Cameron 2008), (Rettler 2015), and (Schaffer 2009).

11 See Sider (2004) and Sider (2011). 
ogists have already latched on to a more fundamental quantifier than the English quantifier, they've already been using it, and that this explains why dismissivists have the complaints they do. ${ }^{12}$

van Inwagen, Quine, and most others with austere ontologies might say that they don't understand the notion of a fundamental quantifier. Or perhaps they would say that the fundamental quantifier just is the English quantifier. van Inwagen, for example, claims that he doesn't believe (i) there are (in the fundamental sense of "there are") no tables, but there are (in the non-fundamental sense of "there are") tables. Rather, he believes (ii) there are no tables. However, he is happy to affirm in certain contexts (like IKEA) that there are tables. The response I am offering the ontologist construes the 'there are' in (ii) as using the fundamental quantifier; when doing ontology, van Inwagen is restricting his attention to things ontologists should care about, which are the fundamental things. van Inwagen would deny this as well, because he thinks the English quantifier is the right one to use when doing ontology. But given that he thinks "there are tables" is true in English when in IKEA and is false in English when doing ontology, and given that he says that 'tables' doesn't change its meaning, there is an internal tension. ${ }^{13}$

Let's bring out the tension a bit more. van Inwagen says, "I say that the sentence 'Chairs exist', when spoken by my imaginary hard-headed cynic - when spoken 'outside' - expresses a different proposition from the one it expresses "inside."' (van Inwagen (2014), p5) And then,

I am one of the philosophers who, when he is "inside" says, "Chairs do not exist." And yet, in my view, the proposition that would be expressed by 'Chairs exist' if it were uttered "outside" in circumstances like those I imagined in the preceding paragraph is true. Let us call the proposition expressed by 'Chairs exist' "inside" and "outside," respectively, the "inside proposition" and the "outside proposition." Few philosophers if any agree with my contention that the inside proposition and the outside proposition are distinct propositions. (van Inwagen (2014), p5)

So, van Inwagen thinks "there are tables" is true when in IKEA and is false when doing ontology because they express different propositions. He also thinks that 'tables' doesn't change its meaning. ${ }^{14}$ But he also says, "It is my firm opinion that there is only one thing for 'exists' to mean and it means that one thing whenever

12 It may not be the most fundamental quantifier, but they're already moving in the direction of the more relatively fundamental.

13 I've seen a few papers that remark in passing that van Inwagen thinks that 'tables' does change its meaning - that van Inwagen thinks that "there are tables" means "there are simples arranged tablewise", which van Inwagen would accept when doing ontology. But he does not think that 'tables' changes its meaning. If by "there are tables" van Inwagen meant "there are simples arranged tablewise", then he would accept "there are tables" in all contexts, because he accepts "there are simples arranged tablewise" in all contexts. But he does not accept "there are tables" in the ontology room.

14 See Sider (2009), §4 and Sider (2011), §9.4. 
and wherever it is used" (van Inwagen (2014), p11). So, van Inwagen believes the sentence "there are chairs" changes its meaning, but 'chairs' doesn't change its meaning, and 'there are' doesn't change its meaning. This is puzzling. van Inwagen does not think that meaning is compositional, so he resists the demand to point to some constituent of the sentence that changes its meaning. For those of us who accept compositional semantics, we must point to some word that changes its meaning in those contexts. And I think the thing to say, pace van Inwagen, is that 'there are' changes its meaning. When van Inwagen utters 'there are' "outside", he means the English quantifier; when he utters 'there are' "inside", it means the fundamental quantifier.

We can generalize this thought to all austere ontologists; they have stopped using the English quantifier when doing ontology. ${ }^{15}$ Once an intelligent person says something like "there aren't any tables or chairs or cars or houses" and proceeds to argue for it, that person has stopped using the English quantifier. ${ }^{16}$

To sum up: the response has three components.

1) The members of the two sides of the ontological debates that dismissivists have targeted are using different existential quantifiers. ${ }^{17}$

2) The austere ontologist is using a more fundamental existential quantifier than her opponent.

15 Though some have then brought their more fundamental quantifier outside of the ontology room and insisted that speakers in IKEA are using it as well. See (Korman,2015b §4.1) for a discussion of this.

16 It is important to note that I do not make any claims about the quantifier of those who we might call 'extravagant ontologists', e.g. Platonists and mereological universalists. I suspect they're trying to figure out what's in the domain of the quantifier with the widest, broadest domain, but arguing for that is another project. On that picture, the austere ontologists are trying to figure out what there is in the most fundamental sense of 'there is', the non-austere-non-extravagant ontologists are trying to figure out what there is in the ordinary sense of 'there is', and the extravagant ontologists are trying to figure out what there is in the most broad sense of 'there is'. Most who deny that there are tables don't deny that in the ordinary sense or the broadest sense of 'there are', there are no tables; and those who do (Merricks) are at pains to provide an error-theory. But someone who denies that there are trout-turkeys may be denying that there are, in the most fundamental sense of 'there are', trout-turkeys; or they may be denying that there are, the ordinary sense of 'there are', trout-turkeys; or they may be denying (and this is what I think they're denying) that even in the most broad sense of 'there are', there are trout-turkeys. Someone who says there are trout-turkeys certainly doesn't think that there are, in the most fundamental sense of 'there are', trout-turkeys; they may think that there are, in the ordinary sense of 'there are', trout-turkeys, and they certainly think that there are, in the most broad sense of 'there are', trout-turkeys.

17 I am taking quantifiers to be semantic values of quantificational expressions, and not themselves expressions. So by 'the English quantifier', I mean the semantic value of the phrase 'there is' or 'there exists' when spoken or written by a typical English speaker in a normal context; this semantic value may or may not be identical to the semantic value of 'es gibt' when spoken or written by a typical German speaker. So, it is consistent with this view that the English and German quantifiers are identical, and it is consistent with this view that the two are distinct. 
3) The austere ontologist's more fundamental existential quantifier is a restriction of her opponent's existential quantifier. ${ }^{18}$

This takes seriously the intuition that there is something wrong with the ontological disputes, but does not entail dismissivism. The majority of the paper is dedicated to arguing for (3). However, there are many who find the phrase "the fundamental quantifier" to be dark or mysterious. So, before arguing for (3), I attempt in the following section to give a bit more content to the notion in the hope of making it a bit more intelligible to such people.

\section{The fundamental quantifier}

There are some ontologists who think that there is a fundamental quantifier that is distinct from the ordinary English quantifier (hereafter 'fundamentality theorists'), and there are some who don't. ${ }^{19}$ Those who don't often say that they can't make sense of what such a thing could be. The present section is an attempt to go some way in explaining what fundamentality theorists are talking about, though I admit that it might be less than fully helpful for someone who doesn't at all understand any notion of fundamentality. $\S 4$ is an attempt to convince fundamentality theorists that the fundamental quantifier is a restriction of the English quantifier.

There seems to be a circle: 'fundamental language', 'fundamental fact', 'fundamental truth', 'fundamental quantifier', 'fundamental predicate', and 'fundamental thing'. The option I favor is to take 'is a fundamental thing' as primitive and define the rest in terms of it. Of course, some will say that the fundamental things are the metaphysical grounds of all true propositions, others will say that they are the things that physicists are talking about and looking for, others will say that they are the truthmakers for all true sentences, still others will say they are the substances, and still others will take it as primitive. Since this option treats 'fundamental thing' as primitive, we shouldn't think we're defining it by 'is an ultimate ground' or 'is a thing physics is looking for' or 'is a truthmaker' or 'is a substance' or what have you. But it might turn out that one of these is co-extensive with 'is a fundamental thing'.

As a first approximation, we can define the rest of the circle in the following way. The fundamental quantifier has in its domain all and only the fundamental things. The fundamental predicates are the predicates that apply to the fundamental things and are such that the true ascriptions of them to the fundamental things make

18 This is pretty much the opposite of what Korman (2008) and Turner (2010) suggest (though don't endorse) when they say that one way of making sense of what ontologists are up to is that in ordinary contexts we're always restricting our quantifiers, but when doing ontology we're not.

19 Those who do include (Sider, 2009, §10ff), Sider (2011), Dorr (2005), Cameron (2010), and Rettler (forthcoming). Those who don't include Merricks (2007), Merricks (2019), Korman (2015a), van Inwagen (1998), McDaniel (2009) and Bohn (2014). 
true all true ascriptions of predicates to things in all languages, and such that there is no proper subset $S$ of them such that the true ascriptions of the members of $S$ to the fundamental things make true all true ascriptions of predicates to things in all languages. ${ }^{20}$ A fundamental language is a language that contains all and only the fundamental quantifier and predicates and terms referring to the fundamental things. The fundamental truths are the truths of the fundamental language, and the fundamental facts are those expressed by the fundamental truths.

These are substantive theses with which people might disagree. But the view is serviceable, and simple, and has only one fundamentality primitive. ${ }^{21}$ In any case, my goal in this section is to go some way in helping non-fundamentality-theorists to understand what fundamentality theorists are talking about. The suggestion is that we're talking about the quantifier that has in its domain all and only the fundamental things. Hopefully the fundamentality of objects seems less mysterious, since it's more familiar, being talked about in the sciences. And hopefully seeing the relations of the notions helps one form a picture of them all.

So, that leaves us with the following view of the fundamental quantifier: $\exists_{1}$ is the fundamental quantifier iff $\exists_{1}$ has in its domain all and only the fundamental things. ${ }^{22}$ We might also add a characterization of relative fundamentality (though this isn't necessary for the present paper): $\exists_{1}$ is more fundamental than $\exists_{2}$ iff $\exists_{1}$ has the same number of (or more) fundamental things and fewer nonfundamental things in its domain as $\exists_{2}$, or $\exists_{1}$ has more fundamental things and the same number of (or fewer) nonfundamental things in its domain as $\exists_{2} .{ }^{23}$

But some people deny that the fundamental quantifier has in its domain all and only the fundamental things. And this is not because there are no fundamental

${ }^{20}$ A referee points out that this seems to require a totality fact, since "one of the things that can be truly ascribed to Socrates is (let's suppose) that he is such that no planet is made of cotton." My view requires that true ascriptions of the fundamental predicates to fundamental things make this true, and being such that no planet is made of cotton presumably is not a fundamental predicate. And if there is some kind of "totality fact" required, it must only involve fundamental predicates. This is serious challenge, but a good response would take us too far afield.

${ }^{21}$ The above referee points out that the definition of "fundamental predicate" makes use of the notion of truth-making, which is plausibly related to fundamentality. So perhaps this view has two fundamentality primitives.

${ }^{22}$ Note that in order to state the view, I had to use a quantifier. Presumably this is the ordinary English quantifier. So according to this view, the domain of the ordinary English quantifier is larger than the fundamental quantifier. Otherwise 'all' wouldn't include all the fundamental things, when 'all' is understood in a non-English, unrestricted sense. (Thanks to Ted Sider for raising this point.)

${ }^{23}$ There is some question as to whether $\exists_{1}$ is more fundamental than $\exists_{2}$ if $\exists_{1}$ has fewer fundamental things and fewer nonfundamental things in its domain than $\exists_{2}$, or if $\exists_{1}$ has more fundamental things and more nonfundamental things in its domain than $\exists_{2}$. I don't wish to take a stand on that; I think it depends on the cases. But I think one can be justified in thinking there are degrees of relative fundamentality without taking a stand on every particular case. 
things (though see; Dasgupta 2009) or no fundamental quantifier distinct from the English quantifier; rather, it is because they think that fundamentality of ideology is not linked, in any interesting sense anyway, to fundamentality of ontology. It might be, on this view, that the fundamental quantifier has in its domain a lot of non-fundamental things. (Of course, given the previous discussion, it must not lack any of the fundamental things.) These people have a different understanding of 'is the fundamental quantifier'; they do not define it in terms of the fundamentality of objects. Rather, they either take 'is the fundamental quantifier' as primitive, or take 'is the fundamental language' as primitive and define 'is the fundamental quantifier' as 'is the quantifier of the fundamental language'. ${ }^{24}$ And of course, they don't define 'is fundamental' as 'is in the domain of the fundamental quantifier', or else they would have to accept that the fundamental quantifier has in its domain all and only the fundamental things. So either they have to give some other definition of 'is fundamental', or take it as an additional primitive.

By way of response, consider the following reductio. There is a set (call it ' $\mathrm{X}$ ') that has as its members all and only the fundamental things. Is the quantifier that has all and only the members of that set in its domain (call it 'exists ${ }_{X}$ ') the fundamental quantifier? Suppose not. Then either the fundamental quantifier has more things in its domain - non-fundamental things, to be sure, since exists ${ }_{X}$ has in its domain all the fundamental things - or it has fewer things in its domain. It cannot have fewer things in its domain, because then there would be some fundamental things that cannot be talked about in the fundamental language, in which case the fundamental language can't be used give the best description of the fundamental nature of reality, which is what it was stipulated to do. So, if the answer is 'no', it must be because the fundamental quantifier has more things in its domain. But this is entirely unmotivated. We'd need a list of which non-fundamental things the fundamental quantifier has in its domain (again, presuming there is a fundamental quantifier distinct from the English quantifier), and a reason why it has those things in its domain and no other things. So, the quantifier that has all and only the fundamental things in its domain is the fundamental quantifier.

On this picture, the fundamental quantifier deserves the distinction 'fundamental' in virtue of having in its domain all and only the fundamental things, but the issue of priority need not be settled in order to proceed. Regardless of which has priority, the fundamental quantifier has in its domain all and only the fundamental things. It seems to me that we will have an easier time figuring out which things are fundamental than which quantifier is fundamental; this is an advantage of the present view, since those who think that fundamental ontology and fundamental ideology come apart cannot figure out which quantifier is fundamental by looking

24 I'm thinking of Sider (2011). 
at the domains of the various candidates. But either approach, if done correctly, will lead to a discovery of both which things are fundamental and which quantifier is fundamental, because of the tight connection between the two.

The fundamental quantifier, $\exists_{F}$, (probably) does not have in its domain chairs, tables, fictional characters, mereological fusions of monuments and body parts, and other such things. ${ }^{25}$ But the English quantifier does have those things in its domain (or at least, tables and chairs and fictional characters). So if the proposed view is correct, then $\exists_{F}$ is a restricted quantifier.

In the following section, I'll argue that if there is a fundamental quantifier, then it's a restriction of the English quantifier, on any reasonable candidate sense of 'restriction'.

\section{Quantifier restriction}

\subsection{A brief overview}

First, a bit on quantifier restriction in general. The usual way to explain quantifier restriction is via fictitious "disputes". Take, for example, a conversation between David and John during a party at John's house. David asks, "Can I have a beer?" John responds, "Yeah, check the fridge." David looks in the fridge and says, "There is no beer!" John replies, "False! There's beer in the garage, and in the store down the corner, and..." David, it seems, has the right to roll his eyes at John. It is quite obvious that when David says, "There is no beer", he is not making the claim that there is no beer anywhere; he is just saying that there isn't any in the fridge. The quantificational phrase "there is" is implicitly restricted to the domain of things in the fridge. I take the following to be a datum: David and John aren't having a real dispute about whether or not there is beer. I take the following to be another datum: the reason John and David aren't having a real dispute is that one is using a restricted quantifier and the other is not. ${ }^{26}$

I turn my attention now to explaining various ways of restricting the quantifier. Each has a claim on our intuitive understanding of restriction, so it's important to

${ }^{25}$ Of course, as Meghan Sullivan pointed out to me, one could think there is a fundamental quantifier that has in its domain simples, chairs, fusions of body parts, fusions of numbers and spacetime points and incars, and so on. Given my view of the relationship between fundamental quantification and fundamental things, that view would say that those things are fundamental; but I cannot make sense of a notion of fundamentality that would allow such things to be fundamental. One who thinks that fusions of numbers and spacetime points and incars are fundamental will have to give what most would consider shocking answers to questions about naturalness, dependence, explanation, grounding, and truthmaking. Or, she will have to say that, despite strong intuitions to the contrary, none of these notions are related to fundamentality. This will make the investigation of what is fundamental difficult to conduct.

${ }^{26}$ Or one is using a more restricted quantifier than the other. 
show that, for each way of restricting a quantifier, the fundamental quantifier is a restriction of the English quantifier in that way. ${ }^{27}$

\subsection{Inferential restriction}

Some think that quantifiers are what they are because of the inferential roles they play. ${ }^{28}$ That is, quantifiers must license the inference rules of existential generalization and existential instantiation. ${ }^{29}$

Existential generalization says if $a$ is $P$, it is provable that something is $P$. Existential instantiation tells us that if something is $P$, it is provable that $a$ is $P$, where we use ' $a$ ' to arbitrarily name an element in the domain - whatever element it is that is $P$. Formally:

Existential generalization: $P a \vdash \exists x P x$

Existential instantiation: If $\phi, P a \vdash Q$, and $a$ doesn't show up in $\phi$ or $Q$ or $P(x)$, then $\phi, \exists x P x \vdash Q$

If quantifiers are partly defined by their inferential roles, then one way to restrict a quantifier is to restrict the inferences one can make. Intuitively: ' $\exists_{2}$ is a restriction of $\exists_{1}$ ' means that for any formula $P$ open in $x$, it is provable from $\exists_{2} x P x$ that $\exists_{1} x P x$, and it is not provable from $\exists_{1} x P x$ that $\exists_{2} x P x .{ }^{30}$ Formally:

$\exists_{2}$ is a restriction ${ }_{I}$ of $\exists_{1}=_{\mathrm{df}}$ (i) For any open formula $\mathrm{P}, \exists_{2} x P x \vdash \exists_{1} x P x$, and (ii) $\neg$ (For any open formula $\left.P, \exists_{1} x P x \vdash \exists_{2} x P x\right)^{31}$

If restriction is understood as restriction ${ }_{I}$, then we have the following explanation of the David and John case. When David says, "There's no beer!" he means that $\neg \exists_{\text {fridge }} x(\operatorname{Beer}(x)){ }^{32}$ His quantifier licenses the inference from $\exists_{\text {fridge }} x P x$ to $\exists_{E} x P x$; from the fact that something fridge $_{\text {is } P \text {, it is provable that something }}$ is $P$. But his quantifier does not license the inference from $\exists_{E} x P x$ to $\exists_{\text {fridge }} x P x$; from the fact that something ${ }_{E}$ is $P$, it is not provable that something fridge $_{\text {is } P \text {, since }} \exists_{\text {fridge }}$

27 As an anonymous referee pointed out, I am assuming that quantifier restriction is a semantic phenomenon, and not a syntactic or pragmatic one. See Stanley and Szabo (2000) for an overview of ways of treating quantifier domain restriction, and arguments for the semantic view. For an example of a syntactic view, see Sellars (1954), and see Collins (2018) for a defense of a syntactic view against Stanley and Szabo's arguments. For an example of the pragmatic approach, see von Fintel (1998) and Bach (2000).

28 See Lewis (2004) and Turner (2010) for treatments of these notions.

29 Thanks to Amelia Hicks and Jason Turner for comments on and discussion of this section.

30 Compare Sider(2007, p. 216)

31 Of course, if one defines 'restriction' as restriction ${ }_{I}$, then it is trivially true that restriction is restriction . But then we would want to know what reasons we have for adopting restriction $_{I}$ as a definition of 'restriction'. The same goes for the other characterizations of restriction.

32 Where $\exists_{\text {fridge }}$ is $\exists_{E}$ restricted to the things in the fridge. 
is a restriction ${ }_{I}$ of $\exists_{E}$. So, there is ${ }_{E}$ beer, but there is fridge $_{\text {no }}$ noer. Since David is using $\exists_{\text {fridge }}$, what he says is true, but John's response is also true, since John is (in this case ridiculously) using $\exists_{E}$.

If $\exists_{F}$ is a restriction $I_{I}$ of $\exists_{E}$, then for any predicate $P$, it is provable from 'something ${ }_{F}$ is $P$ ' that 'something ${ }_{E}$ is $P$ '. This is correct, because everything in the domain of $\exists_{F}$ is in the domain of $\exists_{E}$. When speaking English, we quantify over things that seem to exist, and things that we have good reason to name. We also quantify over the things that our best scientific theories tell us there are. It seems reasonable to think that if scientists discovered super-duper-strings, we would not have to change our quantifier from $\exists_{E}$ to $\exists_{E S}$ (where the latter has in its domain everything that $\exists_{E}$ has plus super-duper-strings) to talk about them. Similarly with discoveries in metaphysics. If metaphysicians were to discover an argument for a new kind of entity that most metaphysicians were to believe was cogent, we wouldn't have to change our quantifier to talk about those entities. So, it seems that the domain of the English quantifier is quite large - large enough to include everything that could count as fundamental, and more things besides. ${ }^{33}$

Things cannot have different properties according to which domain is being used, so the positive inference from 'something ${ }_{F}$ is $P$ ' to 'something ${ }_{E}$ is $P$ ' is licensed. Since the English quantifier has more things in its domain than the fundamental quantifier (like tables and such), the inference from 'something ${ }_{E}$ is $P$ ' to 'something $g_{F}$ is $P$ ' is not licensed. All is as it should be. The goal in using $\exists_{F}$ when doing ontology is to uncover the fundamental ontology of the world; it is to discover the minimal ontology that we need to write the book of the world. If all we needed to do to show that something ${ }_{F}$ is $P$ was to show that something ${ }_{E}$ is $P$, we would not be doing substantive ontology. After all, "tables are wood, therefore something $_{F}$ is wood" is not an inference we want to license. And no fundamentality theorist thinks that the fundamental things don't exist ${ }_{E}$.

Thus, $\exists_{F}$ is a restriction ${ }_{I}$ of $\exists_{E}{ }^{34}$

\subsection{Restriction to a predicate}

Perhaps most quantifier restriction occurs when we restrict a quantifier to a predicate. We ask questions of what there is that is also $P$, where $P$ is filled in with some predicate; we can ask what exists ${ }_{E}$ that is $P$.

33 This is a major difference between natural language quantifiers and the fundamental quantifier. The domains of the natural language quantifier expressions are determined by a combination of use and naturalness, whereas the domain of the fundamental quantifier is determined purely by the fundamentality of the objects in the domain.

34 ' $\exists_{F}$ is a restriction $n$ of $\exists_{E}$ ' does not mean ' $\exists_{F}$ is a restriction ${ }_{n}$ of $\exists_{E}$, and restriction ought to be understood as restriction ${ }_{n}$ '. Rather, it means 'substituting $\exists_{E}$ and $\exists_{F}$ for $\exists_{1}$ and $\exists_{2}$ in the definition of restriction ${ }_{n}$ results in a truth'. 
Intuitively: ' $\exists_{2}$ is a restriction ${ }_{P}$ of $\exists_{1}$ ' means that everything ${ }_{1}$ that is $P$ is identical to something ${ }_{2}$, nothing $g_{1}$ that is $\neg P$ is identical to something ${ }_{2}$, everything ${ }_{2}$ is identical to something ${ }_{1}$, and there is something $g_{1}$ that is not $\mathrm{P}^{35}$ So where $\exists_{U}$ is the unrestricted quantifier and $R$ is the restricting predicate and $\exists_{R}$ is the restricted quantifier, the following are valid: $\forall_{R} x(F x) \equiv \forall_{U} x(R x \supset F x) ; \exists_{R} x(F x) \equiv \exists_{U} x(R x \wedge$ $F x) ; \forall_{U} x(F x) \supset \forall_{R} x(F x){ }^{36}$

Formally, we can define a quantifier ' $\exists_{P}$ ' in the following way:

$$
\left\ulcorner\exists_{P} x(\phi)\right\urcorner=_{\mathrm{df}}\left\ulcorner\exists_{E} x(P x \wedge \phi)\right\urcorner
$$

And we can define restriction ${ }_{P}$ :

$\operatorname{RESTRICTION}_{P}: \exists_{2}$ is a restriction $P$ of $\exists_{1}=_{\mathrm{df}} \forall_{1} x\left(P x \equiv \exists_{2} y(y=x)\right) \wedge \forall_{2} z\left(\exists_{1} y(y=\right.$ z) $\left.\wedge \exists_{1} x(\neg P x)\right)$

Understanding restriction as restriction ${ }_{P}$ lets us give the following explanation of the David and John case. When David tells John, “There's no beer!” he is restricting his quantifier to things in the fridge - present things in the fridge, probably, since beer in the fridge yesterday would not quench David's thirst today. That is, he is saying that there is ${ }_{E}$ no beer that is present and is in the fridge. Substitute 'is present and is in the fridge' for ' $P$ ' in the above formula, and we get David's quantifier $\exists_{\text {fridge }} \cdot\left(\exists_{\text {fridge }}\right)$ is a restriction of John's quantifier $\left(\exists_{E}\right)$.

If $\exists_{F}$ is a restriction ${ }_{P}$ of $\exists_{E}$, then there is ${ }_{E}$ some predicate $P$ such that anything in the domain of $\exists_{E}$ that is $P$ is in the domain of $\exists_{F}$ and everything in the domain of $\exists_{F}$ is in the domain of $\exists_{E}$. Both of these conjuncts are true. The most important step in arguing that both of these conjuncts are true is to identify the predicate in question. ${ }^{37}$ For me, that's easy; the predicate is 'is fundamental' ${ }^{38}$ (Recall my view from $§ 3$.)

If restriction is understood as restriction ${ }_{P}$ and we agree that the predicate we ought to restrict to is 'is fundamental', we can define $\exists_{F}$ :

$$
\left\ulcorner\exists_{F} x(\phi)\right\urcorner=_{\mathrm{df}}\left\ulcorner\exists_{E} x(x \text { is fundamental } \wedge \phi)\right\urcorner
$$

Thus, $\exists_{F}$ is a restriction ${ }_{P}$ of $\exists_{E}$. The goal in using $\exists_{F}$ when doing ontology is to uncover the fundamental ontology - the minimal ontology needed to be the domain

35 This last clause is needed so that quantifiers aren't restrictions of themselves. Thanks to a referee for pointing that out.

36 Thanks to Meghan Sullivan for discussion.

37 Of course, one could phrase it in second-order logic without identifying the predicate: $\exists P\left(\forall_{1} x\left(P x \supset \exists_{P} y(y=x)\right) \wedge \forall_{P} z\left(\exists_{1} y(y=z)\right)\right)$. But which quantifier $\left(\exists_{F}\right.$ or $\left.\exists_{E}\right)$ is the first existential quantifier? Furthermore, if one can avoid second-order logic, one should. Thankfully, we can.

38 I take it that the predicate 'is fundamental' is properly assigned to $x$ if and only if $x$ is in the domain of $\exists_{E}$ and $x$ is fundamental. 
for the quantifier used in the best book of the world. The fundamental ontology is the things in the domain of $\exists_{E}$ that are fundamental.

If $\exists_{F}$ is not a restriction ${ }_{P}$ of $\exists_{E}$, then one of the following is false: (i) everything that is in the domain of $\exists_{E}$ that is fundamental is also in the domain of $\exists_{F}$, or (ii) everything that is in the domain of $\exists_{F}$ is in the domain of $\exists_{E}$. If (i) is false, there are $_{E}$ fundamental things that are not in the domain of $\exists_{F}$. That would be bad, for then the fundamental quantifier doesn't range over all the fundamental things. If (ii) is false, then something in the domain of the fundamental quantifier is not in the domain of the English quantifier; that would also be bad, because then English speakers would somehow be changing their quantifier every time they discovered more fundamental things. The idea is that one looks first at the domain of $\exists_{E}$. The members of that domain include, say $a$ and $b$ and $c$ and...Then one looks at the English sentences containing $\exists_{E}$ and $a$ and $b$ and $c$ and..., and looks for which groups of sentences meet the conditions for being a fundamental description of the world. Then one picks the group that one thinks is the best fundamental description of the world. The things whose names occur in these fundamental sentences will be, say, $a$ and $e$ and $j$ and... Those are the entities in the domain of $\exists_{F}$, quantified over when one uses ' $\exists_{F}$ '. We can do interesting metaphysics using $\exists_{F}$, since it is not an arbitrary restriction.

Another reason to think that everything that exists ${ }_{F}$ also exists $_{E}$ is that quantification in the English language is fluid. When we discovered that electrons existed, we did not have to start speaking a different language in order to talk about them. If we discover that photons have parts, we will not have to start speaking another language to talk about them. This gives us reason to think that the domain of the English quantifier includes a great many things - including things that we have never talked about, and things that we never will talk about. Perhaps it includes everything beings like us could talk about. But at the very least, it includes the fundamental things.

So, $\exists_{F}$ is a restriction ${ }_{P}$ of $\exists_{E}$.

\subsection{Domain restriction}

Another way of restricting a quantifier is to restrict the domain without a restricting predicate. $^{39}$

Intuitively: ' $\exists_{2}$ is a restriction ${ }_{D}$ of $\exists_{1}$ ' means that there is something , $_{1}$ that is not identical to anything ${ }_{2}$ and everything ${ }_{2}$ is identical to something ${ }_{1}$. Formally:

$\operatorname{RESTRICTION}_{D}: \exists_{2}$ is a restriction ${ }_{D}$ of $\exists_{1}=_{\mathrm{df}} \exists_{1} x \neg \exists_{2} y(y=x) \wedge \forall_{2} x \exists_{1} y(y=x)$

39 One might think that for every set, there is a predicate corresponding to that set. If that is the case, then the account of restriction I am about to discuss turns out to be the same as the account in the previous subsection. 
Understanding restriction as restriction ${ }_{D}$ lets us say the following about the David and John case. $\exists_{\text {fridge }}$ is a restriction ${ }_{D}$ of $\exists_{E}$ because there are some things ${ }_{E}$ that are not identical to anything ${ }_{\text {fridge }}$ - the beer at the liquor store down the street, my mother, the electrons in China, and Venus, for example. And there is nothing in the domain of $\exists_{\text {fridge }}$ that is not in the domain of $\exists_{E}$.

The fundamentality theorist should think that the fundamental quantifier is a restriction $_{D}$ of the English quantifier, because the domain of $\exists_{E}$ has more things than the domain of $\exists_{F}$, and there is nothing in the domain of $\exists_{F}$ that is not in the domain of $\exists_{E}$. For example, the domain of $\exists_{E}$ includes tables and knees; the domain of $\exists_{F}$ (probably) does not. ${ }^{40}$ And fundamentality theorists don't think that we are doing substantive ontology when we argue about what things are in the domain of $\exists_{E}$. And as I've argued, everything exists $_{E}$.

\section{Three objections and replies}

Many fundamentality theorists have denied that $\exists_{F}$ is a restricted quantifier. ${ }^{41}$ I am aware of three arguments. In this section, I respond to those arguments.

\subsection{Objection 1}

The first objection is from Ross Cameron:

If it could be shown that the nihilist's sense of 'exists' is a restricted quantifier defined on the universalist's 'exists' that would not be to show that the nihilist and the universalist are talking past each other; it would be to show that the universalist was right after all. $(2008,2)$

The idea here seems to be that if I'm right that the austere ontologist is using a restricted quantifier, then when the universalist says, "there is a fusion of my nose and the Eiffel Tower", she is correct because she's using an unrestricted quantifier. So, the universalist is right! But note that if I' $m$ right, then since the nihilist is using a restricted quantifier, she is also correct when she says to the universalist, "there is no fusion of your nose and the Eiffel Tower". It seems like they're just talking past each other, but then they'd both be right, and Cameron denies this.

Presumably it's because Cameron thinks that the unrestricted quantifier is the one (or unrestricted quantifiers are the ones) we are supposed to use when doing ontology, so the nihilist is just using the wrong quantifier given that she's doing

40 I don't mean to settle any first-order debates about what there is ${ }_{E}$ or what there is ${ }_{F}$. Presumably if one goes in for a fundamental quantifier, one thinks there is something ${ }_{E}$ that there isn' $t_{F}$; so whatever it is, fill it in for 'tables and knees' above.

41 See Cameron (2008), Fine (2009) 163, Lewis (2004), Sider (2009) §11 and 12, and Turner (2010). Additionally, this seems the predominant attitude among metaphysicians at conferences. 
ontology. An analogy will be helpful here. If presentists thought that there are no dinosaurs, but quantifiers wide open there are dinosaurs, then that would be to show that the eternalist is right, and the presentist is simply restricting her quantifier to present things. After all, ontology isn't about what exists now; it's about what exists. That's why presentism is presented as the view that "quantifiers wide open, there are no dinosaurs". 42

But in the case at hand, the austere ontologist doesn't think the unrestricted quantifier $\left(\exists_{E}\right)$ is ontologically perspicuous, and she thinks that sentences using it are not ontologically committing. ${ }^{43}$ Austere ontologists usually think that in at least some contexts it's true to say that there are tables or properties or what have you, but they also usually think that there aren't really those things. They are restricting their quantifiers, but they think the restricted quantifiers are more ontologically perspicuous, and the unrestricted quantifier is just our way of talking about things that aren't really there. ${ }^{44}$ Compare: if presentists thought that (i) there are $_{F}$ no dinosaurs, but (ii) there are ${ }_{E}$ dinosaurs, then that would not be to show that the eternalist is right. After all, fundamentality theorists think that ontology isn't about what there is in the English sense of 'there is'; it's about what exists in the fundamental sense of 'exists'. There is a perfectly sensible view that says that only present things exist ${ }_{F}$, but there are ${ }_{E}$ non-present things - and it's perfectly sensible for fundamentality theorists to count this as a presentist view. ${ }^{45}$ Someone who thinks that the fundamental things are presently existing simples and that they in some way ground the existence of past dinosaurs and future Mars outposts can be quite sensibly counted by fundamentality theorists as a presentist. Similarly, someone who thinks that the fundamental things are mereological simples and that those mereological simples ground the existence of tables can quite sensibly be counted by fundamentality theorists as a mereological nihilist; they think there are tables, but there aren't ${ }_{F}$ tables.

\subsection{Objection 2}

Second, from Sider:

42 See Crisp (2004).

43 See, e.g., Rettler (2015).

${ }^{44}$ Relatedly, see McDaniel (2017), who discusses semantically primitive restricted quantifiers, which he says may be more fundamental than the quantifiers of which they're restrictions.

45 Relatedly, see McDaniel (2017), ch. 3. In particular, presentist existential pluralism (formulated on p. 82), which is the the view that "there are two metaphysically fundamental (possible) meanings for the unrestricted quantifier ' $\exists$ ': ' $\exists_{p}$ ' ranges over all and only past objects, whereas ' $\exists_{c}$ ' ranges over all and only present objects. There is no fundamental quantifier that ranges over objects in both domains." I would classify someone who thinks that $\exists_{p}$ is not fundamental and $\exists_{c}$ is fundamental as a presentist. 
Yet another alternative would be to claim that in the fundamental language, all quantification is restricted. But this would threaten to reintroduce the questions of ontology. For instance, we could ask: "is there any context in which it would be true to say "there are tables and chairs'?" It is hard to see how you could block the legitimacy of this question; and if it is phrasable in your fundamental language, it is substantive and nonverbal. $(2009,418)$

Here Sider is suggesting a way to be an ontological deflationist, someone who thinks that there's something wrong with the ontological questions. One way to be a deflationist, Sider suggests, is to think that there is a fundamental language, but deny that it has a distinguished quantificational structure. One way of denying that there is distinguished quantificational structure in the fundamental language is to claim that all quantification in the fundamental language is restricted. Sider then poses a problem for this view, saying that it still allows distinguished quantificational structure because it allows one to ask the ontological questions indirectly, by asking whether there's a context in which the answer to one of them, like"are there tables", is "yes".

Of course, I don't identify as an ontological deflationist; while I think there's something wrong with the ontological discussion, I don't think there's anything wrong with the questions, as long as they're phrased in the fundamental language. But I do think that the fundamental quantifier is a restricted quantifier, which makes me seem like a target for Sider.

However, I think Sider is making the same assumption that Cameron makes that unrestricted quantification tells us what there really is. When we use restricted quantifiers, the thought goes, we aren't paying attention to some things that really do exist. But I don't think that the fundamentality theorist should think this is true. She should think that the fundamental quantifier tells us what there really is, and unrestricted quantifiers (or the unrestricted quantifier) tell us how we've chosen to talk. Asking whether there's some context in which it would be true to say "there are tables" is just to ask whether we've agreed to talk as though there are tables in some contexts. The question may be substantive and nonverbal, but it is not important or ontological.

\subsection{Objection 3}

Finally, consider the following argument. ${ }^{46}$ We start by introducing a hyperintensional notion of a restricted quantifier: $\exists_{1}$ is a restriction of $\exists_{2}$ iff $\exists_{1} x \phi$ is defined as $\exists_{2} x(\phi \wedge \psi)$, for some $\psi \cdot{ }^{47}$ Then add the following principle: if meaning $m_{1}$ is

46 Thanks to Ted Sider for suggesting (though not endorsing) this argument in correspondence.

47 The notion of definition must be hyperintensional, since the principle entails that 'being $F$ and being $G$ ' is less fundamental than 'being F', even if the two are necessarily co-extensive - for example, if $F$ is $G$. 
defined in terms of meaning $m_{2}$, then meaning $m_{1}$ is less fundamental than meaning $m_{2}$. The principle plus the notion of a restricted quantifier together entail that any restricted quantifier is less fundamental than the quantifier of which it is a restriction.

I think the fundamentality theorist ought to reject the principle. After all, given any quantifier, we can get what this principle considers "less restricted" quantifiers arbitrarily. And in many cases we have no reason to think that the less restricted quantifier is more fundamental than the quantifier we restrict to get it. ${ }^{48}$ Consider some quantifier $\exists_{G}$ that has in its domain $a, b$ and $c$. Introduce a name ' $d$ ', that doesn't name $a$ or $b$ or $c .{ }^{49}$ Then introduce a quantifier ' $\exists_{G d}$, , defined as follows:

$$
\left\ulcorner\exists_{G d} x F x\right\urcorner=_{\mathrm{df}}\left\ulcorner\exists_{G} x F x \vee F d\right\urcorner
$$

Since $\exists_{G d}$ is defined in terms of $\exists_{G}$, the principle tells us that $\exists_{G d}$ is less fundamental than $\exists_{G}{ }^{50}$ This is odd, since $\exists_{G}$ 's domain is a proper subset of $\exists_{G d}$ 's; one might naturally think that $\exists_{G}$ is less fundamental than $\exists_{G d}$ ).

But we can just as easily define $\exists_{G}$ in terms of $\exists_{G d}$. Let's start over, disregarding the previous definition of $\exists_{G d}$. Then we'd say: consider some quantifier $\exists_{G d}$ that has in its domain $a, b, c$ and $d$. Then introduce a quantifier ' $\exists{ }_{G}$ ', defined as follows:

$$
\left\ulcorner\exists_{G} x F x\right\urcorner=_{\mathrm{df}}\left\ulcorner\exists_{G d} x(F x \wedge \neg(x=d))\right\urcorner
$$

So we could take either $\exists_{G}$ or $\exists_{G d}$ as primitive and define the other in terms of it. ${ }^{51}$ According to the principle, which one we chose to take as primitive would determine which one is more fundamental than the other. Note: which one we chose to take as primitive would not just determine which one we ought to think is more fundamental than the other, but which one is in fact more fundamental. This should not be. Which definitions we accept should not determine which bits of our ideology are in fact fundamental.

However we choose to define them, we end up with two quantifiers with their respective domains. It seems as if the relative fundamentality of the things in the

48 The following is an adaptation of the strategy in Turner (2010), 11-12.

49 Indeed, we could even do this with the absolutely unrestricted quantifier. The new name won't name anything new, but the expressive power of the quantifier will still be greater, since there is a new name associated with it.

50 Of course, defining one quantifier in terms of another doesn't guarantee that the defined quantifier has the same meaning as when it's taken as primitive, even though it has the same domain. This is another reason we should reject the principle. For a more familiar example, "green" may not mean the same thing when undefined as it does when defined as "grue if first observed before 2100 and bleen if first observed after 2100". Thanks to an anonymous referee for suggesting this.

51 I am thinking of nominal definitions, not real definitions. Presumably one who thinks of definitions as real definitions would deny that $\exists_{1}$ is a restriction of $\exists_{2}$ only if $\exists_{1}$ is defined in terms of $\exists_{2}$, since the real definition of $\exists_{1}$ might not make any reference to $\exists_{2}$. 
domains of the quantifiers should matter to the relative fundamentality of the quantifier meanings. But on this view, that doesn't matter at all; the only thing that matters is the way at which we arrived at the quantifier meanings. And that doesn't seem right. If one of them is in fact more fundamental than the other, then the principle tells us that there is a right way to define things; and even though both definitions are true, the principle tells us we should reject one of them. And this doesn't seem right.

Compare defining greenness and grueness in the following way: ${ }^{52}$

green $=_{\mathrm{df}}$ grue if first observed before January 1, 2200 and bleen otherwise grue $_{\mathrm{df}}$ green if first observed before January 1, 2200 and blue otherwise

Greenness and grueness are interdefinable; but greenness is more fundamental than grueness, regardless of whether anyone defines greenness in terms of grueness or vice versa. 'Part' and 'proper part' are interdefinable (one could take either parthood or proper parthood as primitive when constructing a mereology) and 'possible' and 'necessary' are interdefinable (one could take either possibility or necessity as primitive when constructing a modal logic), but neither is more fundamental than the other. Nobody would say that choosing to define one in terms of the other is a choice about which to treat as more fundamental. The way that we arrive at a concept of a predicate has nothing to do with how relatively fundamental it is. The same goes with quantifiers. We need to distinguish between how we arrive at the domain of a quantifier and the domain itself. We might arrive at the domain of $\exists_{G d}$ by restricting $\exists_{G}$, or vice versa. That's merely how we get to a quantifier with a certain domain. It doesn't tell us anything about the relative fundamentality of the quantifier itself. ${ }^{53}$

In short, semantic primitivity is orthogonal to fundamentality. Sometimes the meaning of the defined term is more fundamental than the meaning of the term(s) by which it is defined, and sometimes not. The method of introduction of a term should not be a factor in assessing the fundamentality of its meaning.

\section{The neo-Quinean contrast}

The dominant view in meta-ontology is the Quinean view. In this section, I'll compare my view to that view. My view affirms three of the five neo-Quinean theses van Inwagen lays down in his (1998). It affirms that (i) being is not an activity, (ii) being is the same as existence, and (iv) being or existence is adequately captured by

52 Note that we're not merely considering here the interdefinability of 'greenness' and 'grueness'. I am not making a point about terms, but about their semantic content.

53 See again McDaniel (2017), on semantically primitive restricted quantifiers. 
the existential quantifier of formal logic. ${ }^{54}$ The view disagrees with a certain way of thinking about the latter; sometimes 'being' means existence ${ }_{E}$, and sometimes 'being' means existence ${ }_{F}$. If one asks whether being is existence ${ }_{E}$ or existence $_{F}$, the fundamentality theorist says if being is the thing that objects must have in order to figure in the ontology of the world, then being is existence ${ }_{F}$. If being is the thing that some $x$ must have in order for the sentence " $x$ exists" to be true, then being is existence $_{E}$.

(iii) is that 'existence' is univocal. The fundamentality theorist is convinced there is not a single sense of 'existence'. She agrees that each sense of 'existence' can be captured by the existential quantifier of formal logic, in that each sense of 'existence' obeys the introduction and elimination rules of the existential quantifier of first-order logic. If it is true that " $a$ is $F$ ", then it is true that " $\exists_{E} x F x$ ". And if ' $a$ ' names something in the domain of the fundamental quantifier and $a$ is $F$, then it is true that " $\exists_{F} x F x$ ". But since we speak English, regimenting our ordinary discourse into first-order logic is done using the English quantifier. It's not clear how ordinary language maps onto the logic of the fundamental language, but certainly " $a$ is $F$ " expressed in English does not license one to infer that $\exists_{F} x F x$. If someone in the context of doing ontology says "Something is $F$ ", then she is restricting her quantifier to the fundamental, and thus her assertion is that $\exists_{F} x F x$.

The fundamentality theorist also may (and, I think, should) depart from the neo-Quinean with respect to the final neo-Quinean thesis, its criterion of ontological commitment, which van Inwagen explicates as follows:

One takes sentences that the other party to the conversation accepts, and by whatever dialectical devices one can muster, one gets him to introduce more and more quantifiers and variables into those sentences ...If, at a certain point in this procedure, it emerges that the existential generalization on a certain open sentence $F$ can be formally deduced from the sentences he accepts, one has shown that the sentences that he accepts, and the ways of introducing quantifiers and variables into those sentences that he has endorsed, formally commit him to there being things that satisfy F. (246-247)

The fundamentality theorist agrees with this as stated. If existential generalization $_{E}$ on a certain open sentence $F$ can be formally deduced from the sentences one accepts, then one has shown that the sentences that he accepts formally commit him to there being ${ }_{E}$ things that satisfy $F$. And if existential generalization ${ }_{F}$ on a certain open sentence $F$ can be formally deduced from the sentences one accepts, then one has shown that the sentences that he accepts formally commit him to there being $g_{F}$ things that satisfy $F$. But the fundamentality theorist should think that only existence ${ }_{F}$ suffices for ontological commitment. And most of the

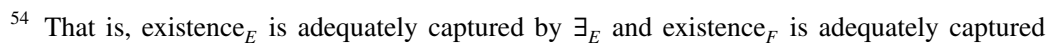
by $\exists_{F}$. 
quantifiers that will be introduced in such a procedure are English quantifiers. But the fundamentality theorist should think that only if the person introduces the fundamental quantifier into his discourse is he ontologically committed to the things over which he quantifies. $^{55}$

One could perhaps be a neo-Quinean and grant all the above about the English quantifier. She would do so by saying that speakers of English very often use 'there is' or 'there exists' idiomatically, and not to express existence. This, she might say, is what the fundamentality theorist is trying to describe with the invo-

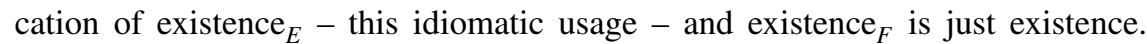
Rather than think 'existence' often expresses existence ${ }_{E}$, this neo-Quinean would say that 'existence' is often used idiomatically and not to express the single sense of 'existence'.

But the neo-Quinean is also very much interested in preventing people from dodging ontological commitment to things over which they quantify by insisting that they're using the quantifier idiomatically so as not to express existence. Quine mandates that in all such cases of purported idiomatic usage of apparently quantificational expressions, one paraphrase one's sentence into a sentence that doesn't use a quantificational expression. If she can't do so, Quine insists, then she is ontologically committed to the things over which she's quantified.

The fundamentality theorist may accept this. She may say that, for any apparent ontologically committing utterance, it must be made explicit which quantifier is being used. If the quantifier is $\exists_{E}$, then no ontological commitment is incurred; but if the quantifier is $\exists_{F}$, then one does incur ontological commitment. And if one utters a sentence using $\exists_{E}$, one must paraphrase the sentence into a sentence using $\exists_{F}$; in this way she makes it clear what her ontological commitments are, and what there is ${ }_{F}$ that provides the underlying ontology for sentences about existence ${ }_{E}$.

But she need not do this. She thinks that one can utter "there are numbers" and still be a nominalist, as long as the semantic value of 'there are' is existence ${ }_{E}$; indeed, nearly every student who says, "there is an even prime" is doing this. She would then say that existence ${ }_{E}$ is not ontologically committing. This fundamentality theorist may think that no further story is necessary; the person uttering the sentence needn't specify which sense of the quantifier expression she's using (she's using $\exists_{E}$ ), nor supply a paraphrase in terms of existence ${ }_{F}$. Such a fundamentality theorist departs more significantly from neo-Quineanism with respect to its criteria of ontological commitment, inasmuch as neo-Quineanism demands a paraphrase.

55 For example, see Rettler (2015). 


\section{Conclusion}

There is a growing movement towards construing some classic debates in ontology as meaningless, either because the answers seem obvious or the debates seem intractable. I have proposed that we understand the debates over what exists as actually being debates over what exists ${ }_{F} ; \exists_{F}$ is the fundamental quantifier, and a restriction of the ordinary English quantifier, $\exists_{E}$. Those who are giving unintuitive answers to the ontological questions are using this restricted quantifier. I have argued that anyone who thinks that there is a fundamental quantifier ought to think that it is a restriction of the ordinary English quantifier. There are three ways of understanding the way we restrict quantifiers: restrictions of the inferential role $\left(\right.$ restriction $\left._{I}\right)$, restrictions to a predicate $\left(\right.$ restriction $\left._{P}\right)$, and restrictions of the domain (restriction ${ }_{D}$ ). The fundamentality theorist should think that $\exists_{F}$ is a restriction of $\exists_{E}$, whichever sense of 'restriction' she accepts.

This solves the problem of debates that seem to have obvious answers and debates that seem intractable. Ontological debates that seem to have obvious answers seem so because they do have obvious answers, at least when the quantifier being used is $\exists_{E}$. But as ontologists, we shouldn't be interested in what exists ${ }_{E}$, but rather what exists ${ }_{F}$. And what things exist ${ }_{F}$ is an open question that should be debated. Debates that seem intractable seem so because ontologists are using different quantifiers and so are talking past each other. When the debate is refocused using $\exists_{F}$, the intractability disappears.

This helps the ontologist in her fight against the dismissivist. Both can agree that there are some ontological disputes that are not substantive. But the ontologist's set of non-substantive disputes will be a proper subset of the dismissivist's. When the dismissivist claims that debates like that over composition are not substantive, the ontologist can disagree. And if the dismissivist claims not to understand why, the ontologist can explain it in terms of quantifier restriction.

We can ask what exists ${ }_{F}$. But that is quite a different question from what exists ${ }_{E}$. The latter often admits of obvious answers; the former usually does not. We can continue to do ontology, then, by arguing about what exists ${ }_{F} \cdot{ }^{*}$

* Thanks to Andrew Bailey, Scott Brown, Ben Caplan, Dirk Kindermann, Alex Pruss, Jeff Russell, Jeff Snapper, and Ted Sider for helpful discussion, and to Kenny Boyce, Dan Korman, Ted Sider, Jeff Speaks, Meghan Sullivan, Jason Turner, Dean Zimmerman, and the audiences at the 2013 Pacific APA, 2013 Western Michigan Metaphysics Workshop, the Baylor University Work-in-Progress Group, and several anonymous referees for providing great comments on early drafts. Special thanks to Mike Rea and Alex Skiles for spending many hours talking through these ideas and commenting on early drafts. Significant revisions to this paper were made while I was supported by a grant from Templeton Religion Trust; the opinions expressed in this publication are those of the author and do not necessarily reflect the views of Templeton Religion Trust. 


\section{REFERENCES}

BACH, K. 2000, "Quantification, Qualification, and Context: A Reply to Stanley and Szabó", Mind and Language, 15, pp. 262-283.

Bennett, K. 2009, "Composition, Coincidence, and Metaontology", in: D. Chalmers, D. Manley and R. Wasserman, eds, Metametaphysics, Oxford: Oxford University Press, pp. 38-76.

Bohn, E. 2014, "Unrestricted Composition as Identity", in: D. Baxter and A. Cotnoir, eds, Composition as Identity. Oxford: Oxford University Press, pp. 143-165.

Cameron, R. 2008, "Truthmakers and Ontological Commitment: Or How to Deal with Complex Objects and Mathematical Ontology Without Getting into Trouble", Philosophical Studies, 140, pp. $1-18$.

Cameron, R. P. 2010, "How to Have a Radically Minimal Ontology", Philosophical Studies, 151, 2, pp. 249-264.

Carnap, R. 1950, "Empiricism, Semantics and Ontology",. Revue International de Philosophie, 4, pp. 20-40. Reprinted in Meaning and Necessity: A Study in Semantics and Modal Logic, 2nd edn, Chicago, IL: University of Chicago Press, 1956.

Chalmers, D. 2009, "Ontological Antirealism", in: D. Chalmers, D. Manley and R. Wasserman, eds, Metametaphysics. Oxford: Oxford University Press.

Collins, C. 2018, "Quantifier Domain Restriction as Ellipsis", Glossa: A Journal of General Linguistics, 3, 60 .

CRISP, T. M. 2004, "On Presentism and Triviality", in: D. W. Zimmerman, ed., Oxford Studies in Metaphysics, vol. 1. Oxford: Oxford University Press, pp. 15-20.

Dasgupta, S. 2009, "Individuals: An Essay in Revisionary Metaphysics", Philosophical Studies, 145, pp. 37-67.

DorR, C. 2005, "What We Disagree About When We Disagree About Ontology", in: M. Kalderon, ed., Fictionalism in Metaphysics, Oxford: Oxford University Press, pp. 234-286.

FIELD, H. 1980, Science Without Numbers, Oxford: Blackwell.

FINE, K. 2009, “The Question of Ontology”, in: D. Chalmers, D. Manley and R. Wasserman, eds, Metametaphysics, Oxford: Oxford University Press, pp. 157-177.

Goggans, P. 1999, "How not to Have an Ontology of Material Objects", Philosophical Studies, 94, pp. 295-308.

HiRSCH, E. 2005, "Physical-Object Ontology, Verbal Disputes, and Common Sense", Philosophy and Phenomenological Research, 70, pp. 67-97.

Hofweber, T. 2009, "Ambitious, yet Modest, Metaphysics", in: D. Chalmers, D. Manley and R. Wasserman, eds, Metametaphysics, Oxford: Oxford University Press.

Jenkins, C. S. 2010, "What is Ontological Realism?" Philosophy Compass, 5, pp. 880-890.

Korman, D. Z. 2008, "Unrestricted composition and restricted quantification", Philosophical Studies, 140, 3, pp. 319-334.

Korman, D. Z. 2015a, "Fundamental Quantification and the Language of the Ontology Room", Noûs, 49, 3, pp. 298-321.

Korman, D. Z. 2015b, Objects: Nothing out of the Ordinary, Oxford: Oxford University Press.

LewIS, D. 2004, "Tensed Quantifiers", in: D. W. Zimmerman, ed., Oxford Studies in Metaphysics, Oxford: Oxford University Press, pp. 3-14.

McDaniel, K. 2009, "Ways of Being", in: D. Chalmers, D. Manley and R. Wasserman, eds, Metametaphysics, Oxford: Oxford University Press, pp. 290-319.

McDaniel, K. 2017, The Fragmentation of Being, Oxford: Oxford University Press.

Merricks, T. 2007, Truth and Ontology, Oxford: Oxford University Press.

Merricks, T. 2019, "The Only Way to Be", Noûs, 53, pp. 593-612.

Putnam, H. 2004, Ethics Without Ontology, Cambridge, MA: Harvard University Press.

Quine, W. V. O. 1948, "On What There Is", Review of Metaphysics, 2, pp. 21-38.

Rettler, B. 2015, "The General Truthmaker View of Ontological Commitment", Philosophical Studies, 173, pp. 1405-1425.

RETTLER, B. forthcoming, "Ways of Thinking about Ways of Being", Analysis.

Schaffer, J. 2009, "On What Grounds What", in: D. Chalmers, D. Manley and R. Wasserman, eds, Metametaphysics, Oxford: Oxford University Press, pp. 347-383.

Sellars, W. 1954, "Presupposing", The Philosophical Review, 63, pp. 197-215. 
Sidelle, A. 2002, "Is There a True Metaphysics of Material Objects?" Philosophical Issues, 12, pp. $118-145$.

Sider, T. 2004, "Replies to Gallois, Hirsch, and Markosian", Philosophy and Phenomenological Research, 58, pp. 674-687.

SIDER, T. 2007, "Neo-Fregeanism and Quantifier Variance", Aristotelian Society Supplementary, 81, pp. 201-32.

Sider, T. 2009, "Ontological Realism”, in: D. Chalmers, D. Manley and R. Wasserman, eds, Metametaphysics, Oxford: Oxford University Press, pp. 384-423.

SIDER, T. 2011, Writing the Book of the World, Oxford: Oxford University Press.

SosA, E. 1999, "Existential Relativity", in: P. French and H. K. Wettstein, eds, Midwest Studies in Philosophy XXIII: New Directions in Philosophy, Oxford: Basil Blackwell, pp. 132-43.

Stanley, J. and Szabo, Z. G. 2000, “On Quantifier Domain Restriction”, Mind and Language, 15, pp. 219-261.

Thomasson, A. L. 2008, "Existence Questions", Philosophical Studies, 141, pp. 63-78.

Thomasson, A. L. 2009, "Answerable and Unanswerable Questions”, in: D. Chalmers, D. Manley and R. Wasserman, eds, Metametaphysics, Oxford: Oxford University Press, pp. 444-71.

Turner, J. 2010, “Ontological Pluralism”, Journal of Philosophy, 107, 1, pp. 5-34.

VAN FraAssen, B. 2002, The Empirical Stance, New Haven, CT: Yale University Press.

VAN INWAGEN, P. 1998, “Meta-Ontology”, Erkenntnis, 48, pp. 233-250.

VAN InWagen, P. 2014, Existence: Essays in Ontology, Cambridge: Cambridge University Press.

von FinTel, K. 1998, "The Semantics and Pragmatics of Quantifier Domains", available at: http://mit. edu/fintel/fintel-1998-qic.pdf. 